\title{
Psychological Distress: Precursor or Consequence of Dating Infidelity?
}

\author{
Julie H. Hall \\ Frank D. Fincham \\ Florida State University
}

Research on infidelity-related distress has focused on victims with little attention to perpetrators. Two studies therefore explore the psychological functioning of individuals who have engaged in dating infidelity. Study 1 showed that, compared to faithful partners, individuals who had engaged in infidelity showed more psychological distress. Study 2 investigated the interrelationships among infidelity, psychological distress, and relationship satisfaction over time. Results suggested that initial levels of psychological distress predicted later infidelity but infidelity did not predict subsequent psychological distress. Findings are interpreted in light of the broader infidelity literature, potential mechanisms are suggested, and avenues for future research are recommended.

Keywords: infidelity; extradyadic involvement; perpetrators; psychological distress; dating

A lthough the majority of Americans expect monogamy from their romantic partners (Wiederman \& Allgeier, 1996), infidelity is widespread in both dating and marital relationships (e.g., Wiederman, 1997; Wiederman \& Hurd, 1999). Infidelity can do irreparable damage to a relationship; extramarital affairs are the leading cause of divorce across 160 cultures (Betzig, 1989) and are one of the most frequent reasons that couples seek marital therapy (e.g., Geiss \& O'Leary, 1981). Although there are a number of betrayals that may occur in the context of a romantic relationship, infidelity is a unique and particularly severe transgression that represents a flagrant violation of the rules or role expectations of most exclusive romantic relationships (Jones, Moore, Schratter, \& Negel, 2001). From an evolutionary perspective, infidelity is far more consequential than other relationship betrayals because of its potential reproductive implications. Men whose partners engage in infidelity risk paternal uncertainty and investing resources in unrelated offspring, whereas women who are victims of infidelity may lose their partners' time, resources, and commitment (e.g., Buss, Larsen, Westen, \& Semmelroth, 1992). Thus, infidelity can be a particularly devastating transgression within romantic relationships.

In addition to causing relationship problems, infidelity affects all parties involved. Injured partners often experience anger, disappointment, self-doubt, depressive symptomatology, and posttrauma-like symptoms in the aftermath of infidelity (see Allen et al., 2005, for a recent review). In contrast, the psychological functioning of perpetrators of infidelity has been largely overlooked by both researchers and practitioners. Nevertheless, there is a small body of research to suggest that perpetrators of infidelity also experience psychological distress. The present studies seek to build on this research.

\section{Psychological Distress Among Perpetrators of Infidelity}

The results of several studies suggest that, like victims, perpetrators of infidelity may experience distress related to extradyadic behavior. Spanier and Margolis (1983) interviewed individuals who had recently separated or divorced their spouse and found that among those who reported engaging in extramarital intercourse during their marriage, more than half reported some degree of

Authors' Note: Portions of this research are based on the first author's doctoral dissertation and were presented at the 2005 and 2006 annual meetings of the Association for Behavioral and Cognitive Therapies in Washington, D.C., and Chicago, respectively. Please address correspondence to Julie Hall, 115 Emery Run, Rochester, NY 14612; e-mail: JulieHHall@gmail.com.

PSPB, Vol. 35 No. 2, February 2009 143-159

DOI: $10.1177 / 0146167208327189$

(C) 2009 by the Society for Personality and Social Psychology, Inc. 
guilt regarding their affair. Among marital-therapyseeking couples, Beach, Jouriles, and O'Leary (1985) found that couples affected by infidelity reported higher levels of depressive symptoms than did the other treatment-seeking couples, with psychological distress being especially high among perpetrators of infidelity. Other studies have also noted heightened levels of guilt and anxiety among individuals who engage in extradyadic behavior (Atwater, 1979; Hunt, 1974; Lawson, 1988).

There is therefore suggestive evidence of guilt and depressive symptoms among perpetrators of infidelity. However, much of this research has concentrated on married or divorced, treatment-seeking samples, resulting in findings that may not generalize to the broader population. In addition, beyond guilt and depressive symptoms, little is known about the types and range of distress that perpetrators may experience. Given the cross-sectional nature of these studies, it is unclear whether psychological distress arises before or after extradyadic involvement. The present studies address these issues by examining a broad range of psychological distress variables among perpetrators of dating infidelity, both within and across time. It should be noted that although there are differences between marital and dating infidelity, there are also many similarities between these populations in terms of unfaithful behaviors, causes, and consequences (Drigotas, Safstrom, \& Gentilia, 1999; Roscoe, Cavanaugh, \& Kennedy, 1988). However, the literature on marital infidelity is substantially larger than that on dating infidelity. Thus, although we draw heavily from the marital literature, we recognize that findings regarding marital infidelity and dating infidelity are not necessarily parallel.

\section{Psychological Distress:}

\section{Precursor or Consequence of Infidelity?}

One possible explanation for the association between infidelity and perpetrator distress is that psychological suffering predicts extradyadic involvement. Atwood and Seifer (1997) found that individuals reported entering into extradyadic involvements at a time when they felt emotionally vulnerable. Low self-esteem and self-acceptance are also associated with infidelity (Sheppard, Nelson, \& Andreoli-Mathie, 1995; Wiggins \& Lederer, 1984). Furthermore, some individuals describe extradyadic involvement as an attempt to enhance their self-confidence and/or combat a sense of inadequacy (Atwood \& Seifer, 1997; Glass \& Wright, 1992). Findings such as these, as well as clinical work with infidelity populations, have led some to hypothesize that psychological distress predicts infidelity (e.g., Buunk \& van Driel, 1989) and that individuals enter into affairs to boost their self-esteem (Elbaum, 1981; Wiggins \& Lederer, 1984). Thus, the current investigation examines whether psychological distress predicts later involvement in dating infidelity.

Alternatively, psychological distress among perpetrators may arise in the aftermath of infidelity. Individuals have a fundamental need to maintain an overall sense of moral and adaptive integrity (Steele \& Liu, 1983). Transgressing against others may threaten one's self-image and invoke dissonance (e.g., Baumeister, 1998), which could be evidenced by psychological distress. Individuals are likely to be especially susceptible to psychological distress following a transgression against their romantic partners (Baumeister, Stillwell, \& Heatherton, 1995), as such transgressions may threaten the positive illusions that are believed to promote good psychological and mental health (Taylor \& Brown, 1988). This has been evidenced in the victim-perpetrator literature, which has shown that relative to victims, perpetrators are more likely to minimize the negative consequences of their actions and to attribute their behavior to external, transitory, and unintentional causes (e.g., Cameron, Ross, \& Holmes, 2002). The current study therefore examines whether infidelity predicts later psychological distress among perpetrators.

\section{Current Studies and Hypotheses}

The goal of the present research was to increase understanding of infidelity by exploring psychological distress experienced by individuals who had been unfaithful to their romantic partners. To accomplish this goal, we conducted two studies. In Study 1, we attempted to replicate and extend past research by broadly examining the psychological functioning of individuals who had been unfaithful to their current romantic partners as compared with individuals who had remained faithful. We hypothesized that perpetrators of infidelity would experience greater psychological distress than individuals who had not engaged in extradyadic behavior. Study 2 built on the results of Study 1 by testing hypotheses regarding the temporal association between infidelity and psychological distress. Using longitudinal data obtained from individuals in dating relationships, we examined whether psychological distress was best described as a precursor or consequence of infidelity.

\section{STUDY 1: PSYCHOLOGICAL DISTRESS AMONG INDIVIDUALS WHO HAVE BEEN UNFAITHFUL TO THEIR CURRENT ROMANTIC PARTNER}

The goal of our first study was to determine whether perpetrators of infidelity reported more psychological 
distress than other individuals in romantic relationships. With the intent of replicating and extending past research, a broad range of variables representing psychological distress were assessed, including depressive symptoms, anxiety, general well-being, guilt, shame, self-forgiveness, and trauma symptomatology. We studied a college dating sample to determine whether prior findings that focused on married and/or treatment-seeking samples extend to this population.

\section{Method}

\section{Participants}

Participants were 287 students (95 male, 192 female) enrolled in an introductory psychology course (mean age = 19.5 years) who volunteered to take part in partial fulfillment of course requirements. All were currently involved in an exclusive dating relationship of at least 4 months (average length $=20.3$ months). ${ }^{1}$ Several ethnic groups were represented (65\% Caucasian, 18\% Asian, $8 \%$ African American, 7\% Latino/Latina, 2\% Other).

\section{Procedure}

Participants completed a packet of questionnaires in the laboratory. These questionnaires included general measures of psychological distress as well as offense-specific measures of distress. All participants completed general measures of depression, anxiety, and well-being. Participants then completed measures of infidelity, followed by offense-specific measures of guilt, shame, self-forgiveness, posttrauma symptomatology, and transgression severity. Those who reported infidelity completed these offense-specific measures with regard to their unfaithful behavior, whereas those who did not report infidelity were asked to describe the most serious transgression they had committed against their partner and then completed the offensespecific measures with regard to that transgression.

\section{Measures}

Center for Epidemiological Studies Depression Scale (CES-D; Radloff, 1977). The CES-D is a self-report measure that asks respondents to rate the frequency of depressive symptoms experienced over the past week (e.g., "I felt sad"). Items are rated on a 4-point scale, ranging from rarely or none of the time to most or all of the time, with higher scores indicating more symptoms. The CES-D has good psychometric properties (Radloff, 1977) and had a Cronbach's alpha of .90 in the current study.

Beck Anxiety Inventory (BAI; Beck \& Steer, 1990). The BAI is a 21-item self-report measure used to assess anxiety symptoms (e.g., "numbness or tingling," "feeling hot"). Participants rated the frequency with which they had experienced each item over the past week, using a 4-point scale ranging from not at all to severely. The items were summed such that greater scores indicated greater levels of anxiety. The BAI has demonstrated adequate reliability and validity (Beck, Epstein, Brown, \& Steer, 1988) and had a Cronbach's alpha of .89 in the current study.

General Well-Being Schedule (GWS; Dupuy, 1978). The Positive Well-Being subscale of the GWS (three items) was used to measure subjective feelings of psychological well-being and distress over the past month (e.g., "How have you been feeling in general during the past month?"). Items were reverse scored, so that higher scores reflected greater well-being. The GWS has demonstrated excellent internal consistency, test-retest reliability, and adequate convergent and construct validity (Fazio, 1977; Himmelfarb \& Murrell, 1983). In the current study the subscale had a Cronbach's alpha of .76.

Actual extradyadic involvement or transgressions against partner. Participants were asked whether they had ever done anything physically and/or emotionally unfaithful to their current partner (yes-no). Those who responded "yes" were asked to characterize their extradyadic behavior as sexual, emotional, or both sexual and emotional. They also provided some descriptive information regarding the infidelity, including how long the involvement lasted, when it ended, and whether their primary partner was aware of the behavior. These participants were asked to complete the remaining measures with regard to their unfaithful behavior. Participants who indicated that they had not been unfaithful were asked to think about the most hurtful thing they had ever done to their partner and to complete the remaining measures with regard to that transgression. Transgressions that participants listed included: saying something hurtful, lying, breaking a promise, exhibiting uncaring behavior, and so on.

State Shame and Guilt Scale (SSGS; Marschall, Sanftner, \& Tangney, 1994). Participants were asked to complete this measure with regard to how they felt when thinking about their behavior (i.e., infidelity or other transgression). The Shame subscale of this measure comprises five items that measure in-the-moment shameful feelings (e.g., "I want to sink into the floor and disappear"). The Guilt subscale consists of five items that measure current guilty feelings (e.g., "I feel remorse, regret"). These items were rated on a 5-point Likert-type scale $(1=$ not feeling this way at all, $5=$ feeling this way very strongly), such that higher scores indicated greater levels of shame or guilt. Both subscales have high internal consistency (Marschall et al., 1994) 
and adequate test-retest reliability (Hall \& Fincham, 2008). In the current study, both subscales had Cronbach's alphas of .85 .

Self-forgiveness. We measured participants' levels of self-forgiveness with a single item that was completed with regard to their unfaithful behavior (when applicable) or with regard to the most serious transgression they had ever committed against their romantic partner. Participants were asked to "rate the extent to which you forgive yourself" using a 7-point Likert-type scale ( $1=$ not at all, $7=$ completely).

Impact of Event Scale-Revised (IES-R; Weiss \& Marmar, 1997). The IES-R is a 22 -item self-report measure designed to examine posttrauma symptoms. Participants completed this measure with regard to their transgression (i.e., infidelity or other offense). Items were rated on a 5-point scale ranging from not at all to extremely and summed such that higher scores indicated greater distress. In the current study, two subscales of this measure were used that assessed intrusions (e.g., "I thought about it when I didn't mean to") and avoidance (e.g., "I tried not to think about it"). These subscales have shown good internal consistency and test-retest reliability (Weiss \& Marmar, 1997). In the current study, Cronbach's alphas for the Intrusion and Avoidance subscales were .91 and .88, respectively.

Transgression severity. Transgression severity was measured using a single item that asked participants how upset their partner was or would be by their behavior (i.e., infidelity or other transgression). This item was rated on a 7-point scale ranging from not upset at all to the most upset I have even seen him/her.

\section{Results}

\section{Descriptive Information}

Thirty-five percent of the participants $(n=101)$ indicated that they had been physically and/or emotionally unfaithful to their current romantic partner. Of those who had engaged in infidelity, $29 \%$ classified their behavior as physical infidelity, $28 \%$ labeled it emotional infidelity, and the remaining $43 \%$ considered their behavior to be both physically and emotionally unfaithful. Although we lacked adequate power to statistically compare distress levels among these groups, descriptive data are provided in Table 1. In general, distress levels were highest among the physically and emotionally unfaithful group.

Approximately one third (29\%) of participants endorsing infidelity reported "one-night stands" or involvements lasting less than $24 \mathrm{hr}$. Others (50\%) described extradyadic relationships lasting from 1 to 4 weeks; relatively few participants $(21 \%)$ endorsed more long-term involvements. Only $17 \%$ reported that the infidelity was still ongoing; most participants reported that it had ended within the past month $(22 \%)$, past year $(46 \%)$, or more than 1 year before the study $(15 \%)$.

A modest number of those who had engaged in infidelity $(35 \%)$ reported that their primary partner was fully aware of the infidelity. Nineteen percent indicated that their partner knew some of details of the infidelity, and the remaining $46 \%$ reported that their partner was unaware of their extradyadic involvement or that they were unsure of their partners' level of awareness. Mean distress levels for these various subgroups are provided in Table 1 but were not statistically compared because of limited power. In general, distress levels were highest among those whose partners were somewhat aware of the infidelity but did not know all of the details.

\section{Statistical Analyses}

Zero-order correlations among the dependent variables are displayed in Table 2. To compare the psychological distress experienced by perpetrators and nonperpetrators of infidelity, a MANOVA was performed with infidelity as the independent variable, and measures of depression, anxiety, general well-being, guilt, shame, posttrauma symptomatology (i.e., intrusions and avoidance), and self-forgiveness as the dependent variables. The overall MANOVA was significant, $F(8,274)=9.26, p<.001$, indicating that individuals who engaged in infidelity experienced significantly different levels of psychological distress than those who did not engage in infidelity. ${ }^{2}$

Univariate analyses (see Figure 1) revealed that unfaithful individuals experienced significantly greater levels of depressive symptomatology, $F(1,285)=23.99$, $p<.001$, and lower levels of general well-being, $F(1$, $284)=13.32, p<.001$, than those who had not engaged in infidelity. However, the two groups did not differ in their general levels of anxiety, $F(1,284)=1.19$, ns. In terms of offense-specific distress, individuals who had been unfaithful reported greater guilt, $F(1,284)=22.6$, $p<.001$, and shame, $F(1,284)=21.93, p<.001$, than those who had not been unfaithful. Perpetrators of infidelity also reported significantly more intrusions, $F(1$, $283)=28.6, p<.001$, and avoidance, $F(1,283)=43.86$, $p<.001$, than those who had not engaged in infidelity. Finally, perpetrators of infidelity reported lower levels of self-forgiveness than other individuals, $F(1,283)=$ $27.52, p<.001$.

Although perpetrators of infidelity reported greater psychological distress than individuals who committed other 


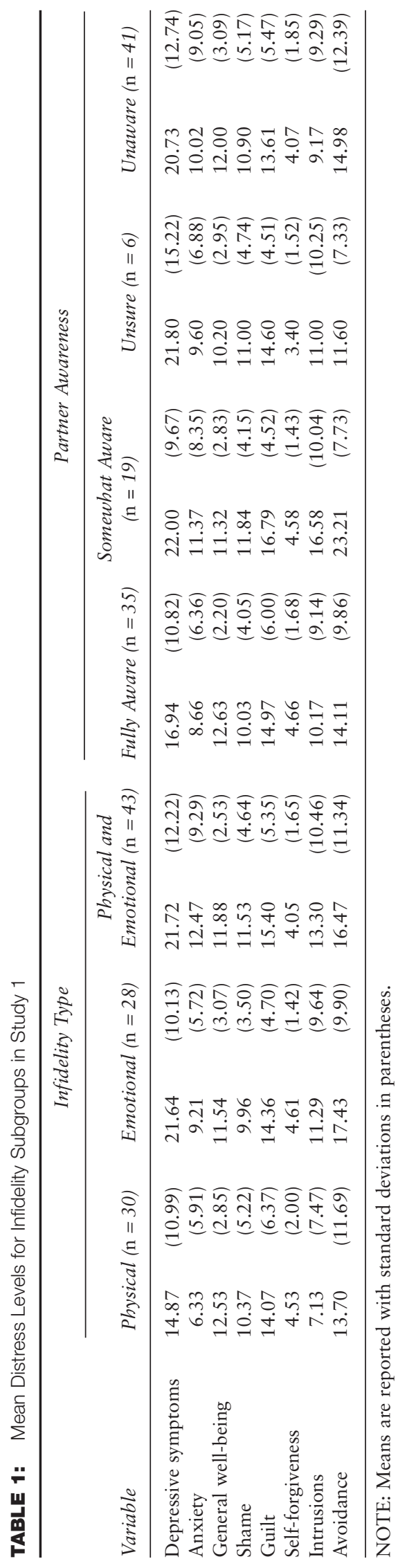


TABLE 2: Correlations Among Dependent Variables in Study 1

\begin{tabular}{|c|c|c|c|c|c|c|c|c|c|}
\hline Variable & 1 & 2 & 3 & 4 & 5 & 6 & 7 & 8 & 9 \\
\hline 1. Depressive symptoms & - & & & & & & & & \\
\hline 2. Anxiety & $.59 * *$ & - & & & & & & & \\
\hline 3. General well-being & $-.57^{* *}$ & $-.32 * *$ & - & & & & & & \\
\hline 4. Shame & $.31 * *$ & $.26 * *$ &.$- \overline{14} *$ & - & & & & & \\
\hline 5. Guilt & $.21 * *$ & $.21 * *$ & -.08 &.$\overline{74} * *$ & - & & & & \\
\hline 6. Self-forgiveness & $-.28 * *$ & $-.17 * *$ & $.26 * *$ & $-.43^{* *}$ &.$- \overline{49 * *}$ & - & & & \\
\hline 7. Intrusions & $.27 * *$ & $.20 * *$ & $-.14 *$ & $.25 * *$ & $.38 * *$ &.$- \overline{33} * *$ & - & & \\
\hline 8. Avoidance & $.30 * *$ & $.17 * *$ & $-.16^{* *}$ & $.34 * *$ & $.45 *$ & $-.36^{* *}$ & $.73^{*} *$ & - & \\
\hline 9. Transgression severity & .11 & .02 & -.11 & $.17 * *$ & $.25 * *$ & $-.20 * *$ & $.19 * *$ &.$\overline{22 * *}$ & _ \\
\hline
\end{tabular}

$* p<.05 . * p<.01$.

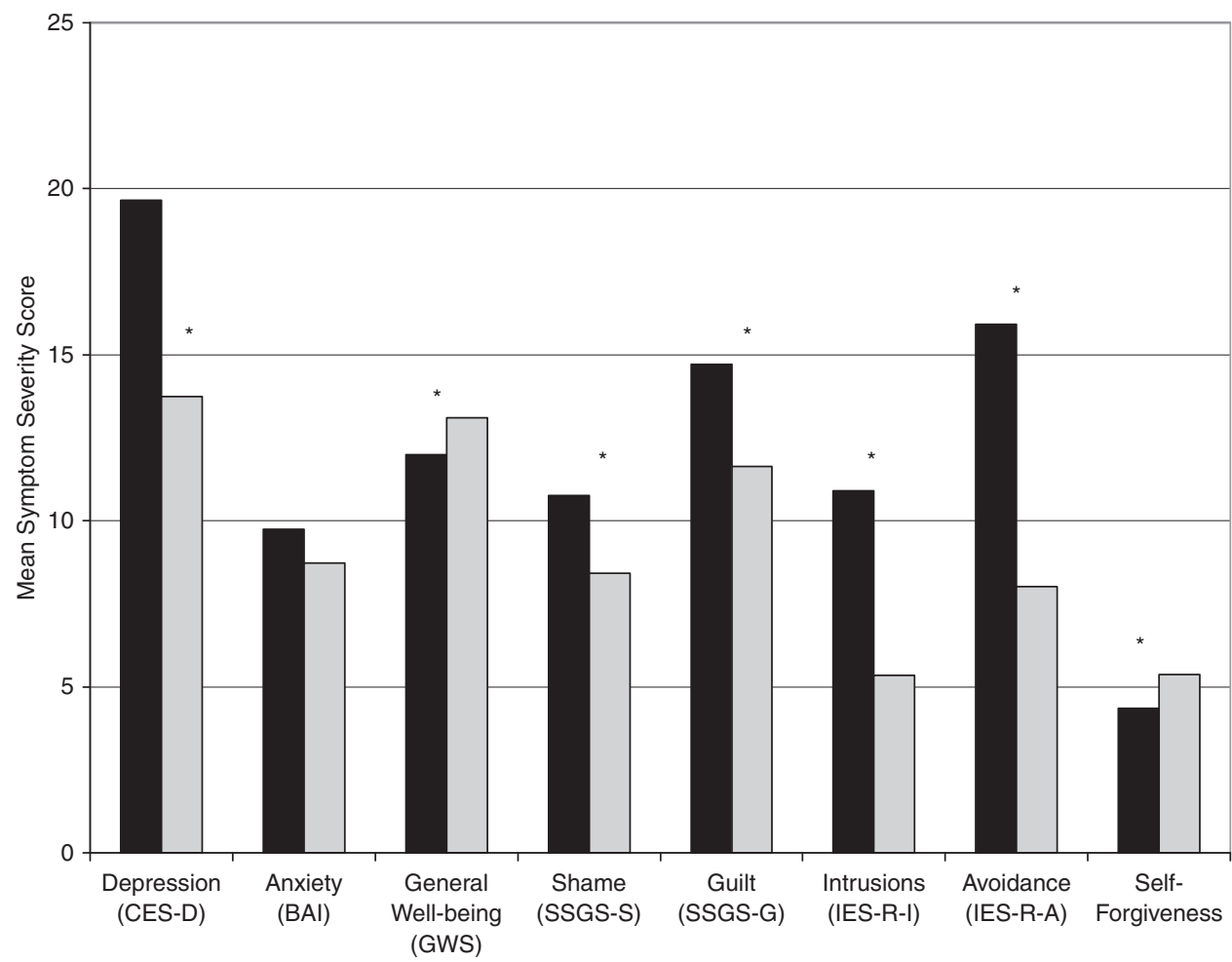

Unfaithful Partners $\square$ Faithful Partners

Figure 1 Differences in psychological distress among faithful and unfaithful partners in Study 1.

NOTE: Measures based on different scales. Scale maximums are as follows: Center for Epidemiological Studies Depression Scale (CES-D) =60; Beck Anxiety Inventory $(\mathrm{BAI})=63$; General Well-Being Schedule (GWS) =16; State Shame and Guilt Scale (Shame subscale; SSGS-S) = 25, State Shame and Guilt Scale (Guilt subscale; SSGS-G) = 25; Impact of Event Scale-Revised (Intrusions subscale; IES-R-I) = 35, Impact of Event Scale-Revised (Avoidance subscale; IES-R-A) $=40$, Self-Forgiveness $=7$. $* p<.05$.

transgressions, this finding may have been driven by the fact that infidelity was an inherently more severe transgression $(M=5.88)$ than those reported by the comparison group $(M=4.99), t(283)=5.01, p<.001$. To rule out this possibility, transgression severity was entered as a covariate in the ANOVA analyses. However, the initial results held after controlling for this variable, suggesting that our findings did not reflect differences in transgression severity.

\section{Discussion}

The present findings replicate and extend the existing literature on infidelity, suggesting that individuals who have been unfaithful to their romantic partners report significantly more psychological distress than those who have not engaged in infidelity. In terms of general distress, perpetrators of infidelity reported greater depressive 
symptoms and lower general well-being than other individuals. Individuals who had engaged in extradyadic behavior also expressed more offense-related distress than faithful partners, as indicated by their greater levels of shame, guilt, intrusions, and avoidance, as well as lower levels of self-forgiveness. Interestingly, these data also suggest that variables such as infidelity type and partner awareness should be explored as potential moderators in future research. Individuals who engage in infidelity that is both physical and emotional may be prone to greater distress, as such infidelity is considered more morally and socially unacceptable (e.g., Sheppard et al., 1995). In addition, those whose partners are aware of some, but not all, details of the infidelity may be prone to greater distress. This may reflect concern over possible consequences if their partners should discover the full extent of the infidelity.

Overall, these results are among the first to show that individuals who have been unfaithful to their current partner appear to be experiencing more psychological problems than their faithful counterparts. Furthermore, our use of a nonclinical, college sample suggests that such distress is not specific to married and/or treatmentseeking samples. However, this study was limited by the possibility that the greater distress among perpetrators of infidelity may have merely reflected their experience of being in a more distressed relationship, a very credible possibility given the documented association between relationship distress and psychological symptoms (e.g., Whisman, Uebelacker, \& Weinstock, 2004). Furthermore, it was unclear whether the psychological distress experienced by perpetrators arose before or after the infidelity. In light of these limitations we conducted a second study that sought to build on the findings of Study 1 by exploring the interrelationship among infidelity, psychological distress, and relationship satisfaction over time.

\section{STUDY 2: A LONGITUDINAL EXAMINATION OF PSYCHOLOGICAL DISTRESS, INFIDELITY, AND RELATIONSHIP SATISFACTION AMONG INDIVIDUALS IN DATING RELATIONSHIPS}

Study 2 built on the findings of the first study to pinpoint whether psychological distress was best described as a precursor or consequence of dating infidelity. Although Study 1 suggested that perpetrators of infidelity experienced greater levels of psychological distress than other individuals in dating relationships, the cross-sectional nature of the data precluded us from examining the direction of effects. Thus, the current study explored the interrelationship of these constructs over time.
The model hypothesized to explain the longitudinal associations among infidelity, relationship quality, and psychological distress is shown in Figure 2. The relationship between infidelity and psychological distress was the primary focus of this investigation. Given conflicting data regarding this association (i.e., distress predicting infidelity vs. infidelity predicting distress) and a lack of prior longitudinal data, two hypotheses were examined. Consistent with dissonance theory, we hypothesized that Time 1 infidelity would predict significant psychological distress at Time 2 (Path a). The alternate possibility that Time 1 psychological distress would predict Time 2 infidelity was also incorporated in this initial model (Path b). However, it was plausible that support would be found for both hypotheses.

Although individual distress was of primary interest, relationship quality was also included in the model because of its potential reciprocal relationship with infidelity. Drawing from preliminary evidence suggesting a temporal association between low levels of relationship quality and subsequent involvement in extradyadic behavior (e.g., Oikle, 2003), we expected that Time 1 relationship quality would predict infidelity at Time 2 (Path c). In addition, there is evidence that being unfaithful to one's partner may erode self-reported relationship quality over time (Drigotas et al., 1999). Therefore, we also predicted that infidelity at Time 1 would be related to lower levels of relationship quality at Time 2 (Path d).

Past research supports an association between relationship quality and psychological distress, independent of infidelity (e.g., Whisman et al., 2004). For example, there is ample evidence that relationship distress is prospectively associated with depression, as well as findings that depression precedes relationship distress (e.g., Beach \& O'Leary, 1993). Thus, the proposed model included paths between Time 1 psychological distress and Time 2 relationship quality (Path e) and Time 1 relationship quality and Time 2 psychological distress (Path f). Finally, the model included paths between each Time 1 variable and its respective Time 2 variable (Paths g-i), as well as covariances among variables within time and correlated measurement errors over time (Kline, 1998).

\section{Method}

\section{Participants}

Participants were 284 volunteer undergraduate students (94 male, 190 female) who received partial fulfillment of the requirements for an introductory psychology class (mean age $=19.4$ years). All were currently involved in an exclusive, heterosexual dating relationship of at least 4 months. Participants had, on average, been involved with their partner for approximately $1 \frac{1 / 2}{2}$ years 


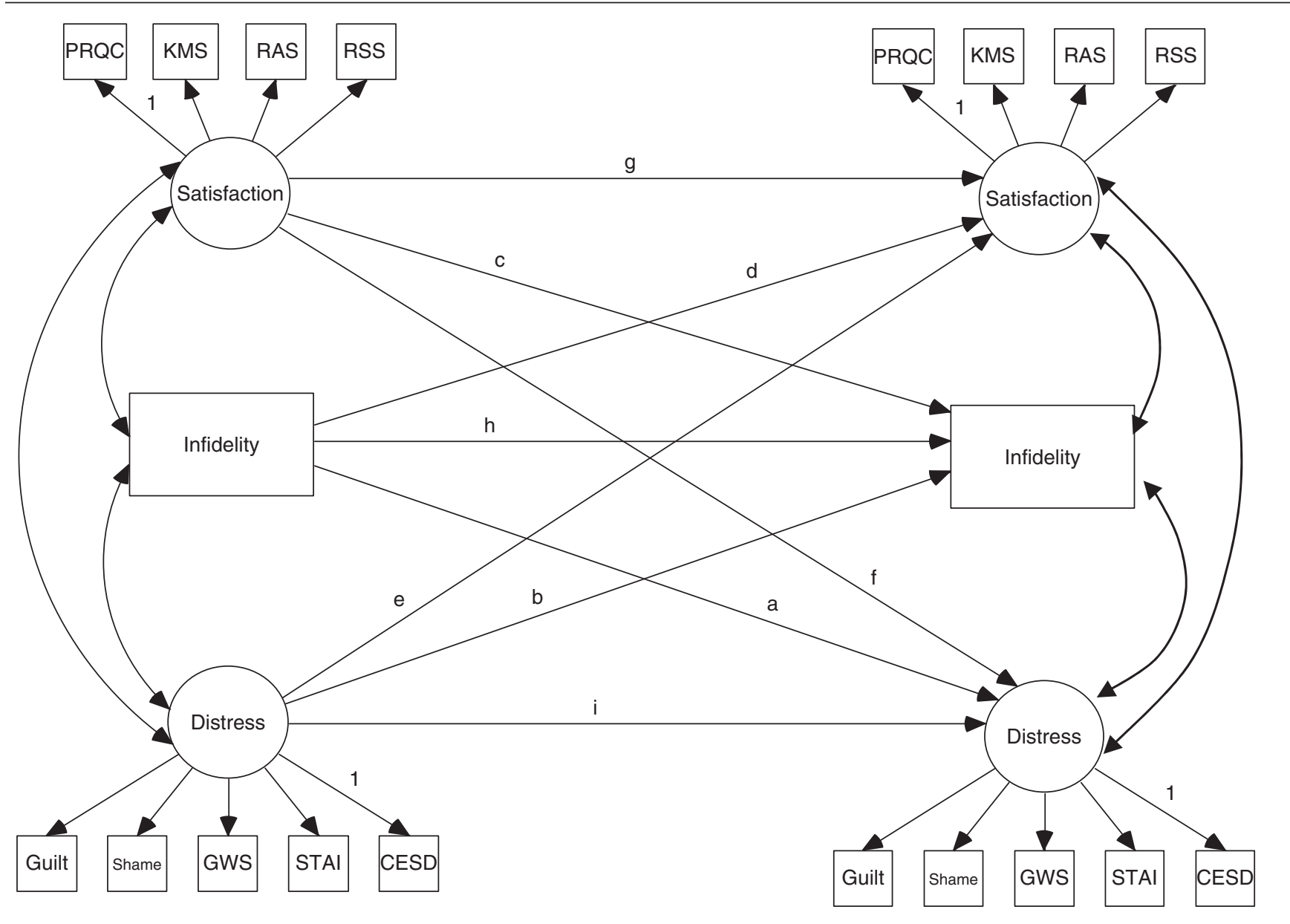

Figure 2 Full hypothesized hybrid model.

NOTE: For clarity purposes, residual variances, errors, and disturbances are not included. PRQC $=$ Perceived Relationship Quality Components Scale; KMS = Kansas Marital Satisfaction Scale; RAS = Relationship Assessment Scale; RSS = Relationship Satisfaction Scale; GWS = General Well-Being Schedule; STAI = State-Trait Anxiety Inventory; CESD = Center for Epidemiological Studies Depression Scale.

( $M=19.10$ months). Several ethnic groups were represented $(65 \%$ Caucasian, $16 \%$ Asian, $10 \%$ African American, 4\% Latino/Latina, 5\% Other). Approximately $6 \%(n=16)$ of the original sample dropped out of the study between Time 1 and Time 2 assessments. This final sample also did not include 50 additional participants who attended the initial session but were no longer involved with the same romantic partner at Time 2. Data from these participants were excluded from all analyses because of concerns about possible confounds (e.g., distress attributable to relationship termination).

\section{Procedure}

Participants signed up for an initial session and for a follow-up session scheduled exactly 4 weeks after the original assessment. At each time point, participants came into the laboratory in groups of 4-5 and completed informed consent forms and the study questionnaires. In addition to filling out study questionnaires, participants were asked to provide standard demographic information and to confirm the status of their relationship at each assessment.

\section{Measures}

Perceived Relationship Quality Components Scale (PRQC; Fletcher, Simpson, \& Thomas, 2000). The PRQC is an 18-item self-report measure that was used to assess perceived relationship quality over the past month (e.g., "How much could you count on your partner?"). Participants were asked to respond to each item using a 7-point Likert-type scale ranging from not at all to extremely. This measure has demonstrated adequate internal consistency and test-retest reliability (Fletcher et al., 2000). 
Kansas Marital Satisfaction Scale (KMS; Schumm et al., 1986). The KMS was adapted to measure relationship satisfaction over the past month. Items were reworded to apply to dating relationships (e.g., "marriage" changed to "relationship"). This measure consists of three items (e.g., "How satisfied were you with your boyfriend/girlfriend as a partner?") that participants rated on a 7-point Likert-type scale (extremely dissatisfied to extremely satisfied). Higher scores indicated greater relationship satisfaction. The KMS has shown excellent internal consistency and concurrent validity in married samples (Schumm et al., 1986).

Relationship Assessment Scale (RAS; Hendrick, 1988). The RAS is a seven-item self-report measure that was used to assess the quality of participant's romantic relationships over the past month (e.g., "How well did your partner meet your needs?”). Participants rated each item on a 5-point Likert-type scale, with higher scores indicating greater satisfaction. The RAS has demonstrated good psychometric properties in dating samples (e.g., Hendrick, 1988).

Relationship Satisfaction Scale (RSS; Rusbult, 1983). This three-item scale yields a global measure of relationship satisfaction, with higher scores indicating greater satisfaction (e.g., "Over the past month, how much did you like your partner?"). This measure has shown good psychometric properties in dating samples (e.g., Rusbult, 1983).

CES-D (Radloff, 1977). Similar to Study 1, the CES-D was used to measure depressive symptomatology. Although participants are typically asked to consider the past week when making such ratings, the current study instructed participants to consider the past month to be consistent with the other measures.

State-Trait Anxiety Inventory (STAI; Spielberger, Gorsuch, \& Lushene, 1970). The STAI is a 40 -item measure that assesses both state (STAI-S) and trait anxiety (STAI-T). Participants endorsed each item using a 4-point scale, ranging from not at all to very much so. The STAI has good internal consistency and test-retest reliability (Spielberger, Gorsuch, Lushene, Vagg, \& Jacobs, 1983). Only the State Anxiety subscale was used in the current study (e.g., "I was tense"; "I felt strained").

GWS (Dupuy, 1978). The full version of the GWS was used to measure subjective feelings of psychological well-being over the past month.

SSGS (Marschall et al., 1994). As in Study 1, the SSGS was used to measure levels of shame and guilt over the past month.
Extradyadic Experiences Questionnaire (EEQ; Allen of Baucom, 2004). The EEQ is a questionnaire that was designed to assess patterns of extradyadic involvement. Several questions from this measure were used to examine the extent of participants' extradyadic involvement over the past month. For example, participants were asked to indicate how often they engaged in certain behaviors (e.g., passionate kissing, sexual hugging and caressing) with someone other than their primary partner. These questions were used to objectively measure infidelity, as participants may or may not have considered these behaviors to be unfaithful. An individual was objectively considered to have engaged in infidelity if he or she endorsed any of these behaviors.

Subjective extradyadic involvement. Participants were asked whether they had done anything within the past month that they considered physically and/or emotionally unfaithful to their primary partner (yes-no). Participants were also asked whether they had done anything within the past month that their partner would consider to be physically and/or emotionally unfaithful (yes-no). These questions served as a subjective measure of infidelity, as they required participants to evaluate their fidelity based on the norms and expectations of their unique romantic relationship. Participants were also asked to provide some descriptive information regarding the infidelity at Time 1 , including the type of infidelity, how long the involvement lasted, when it ended, and whether their primary partner was aware of the behavior.

\section{Results}

\section{Data Analytic Strategy}

Study hypotheses were tested using hybrid structural equation modeling in Mplus, Version 3.11 (B. O. Muthén \& Muthén, 2004).3 Given the binary and skewed nature of the infidelity variables, a robust weighted least squares estimator was used in modeling the data. Psychological distress and relationship satisfaction were represented as latent variables; thus, a twostep modeling approach was adopted, as this method has been recommended when estimating hybrid models (Kline, 1998).

\section{Descriptive Statistics and Preliminary Analyses}

Means, standard deviations, ranges, and internal consistencies for all variables at Time 1 and Time 2 are reported in Table 3, and correlations among these variables are presented in Table 4 . As previously mentioned, approximately $6 \%$ of the sample was lost to attrition, and $t$ tests revealed no significant differences in study variable scores when comparing these individuals with the remainder of the sample. 
TABLE 3: Means, Standard Deviations, Ranges, and Internal Consistencies for Continuous Study 2 Variables

\begin{tabular}{|c|c|c|c|c|c|c|}
\hline Variable & Overall $\mathrm{M}$ & $\begin{array}{c}\text { Infidelity } \\
\text { Subgroup M }\end{array}$ & $\begin{array}{l}\text { Noninfidelity } \\
\text { Subgroup M }\end{array}$ & SD & Range & $\begin{array}{c}\text { Internal } \\
\text { Consistency }\end{array}$ \\
\hline PRQC (T1) & 36.41 & 34.85 & 37.63 & 4.15 & $23-42$ & .76 \\
\hline PRQC (T2) & 36.82 & 33.39 & 37.48 & 5.00 & $17-42$ & .83 \\
\hline KMS (T1) & 17.48 & 17.06 & 18.07 & 2.64 & $9-21$ & .93 \\
\hline KMS (T2) & 17.76 & 16.37 & 18.37 & 3.56 & $3-21$ & .96 \\
\hline RAS (T1) & 28.75 & 28.23 & 29.76 & 4.33 & $16-35$ & .81 \\
\hline RAS (T2) & 29.56 & 26.98 & 30.05 & 4.76 & $12-35$ & .85 \\
\hline RSS (T1) & 22.36 & 20.95 & 23.44 & 4.37 & $8-27$ & .70 \\
\hline RSS (T2) & 23.50 & 21.44 & 24.14 & 4.47 & $4-27$ & .85 \\
\hline CES-D (T1) & 15.99 & 16.91 & 14.35 & 10.22 & $0-45$ & .91 \\
\hline CES-D (T2) & 15.95 & 20.41 & 13.84 & 10.99 & $0-49$ & .92 \\
\hline STAI (T1) & 40.32 & 40.12 & 38.93 & 11.74 & $20-79$ & .94 \\
\hline STAI (T2) & 39.20 & 44.37 & 36.54 & 11.96 & $20-72$ & .95 \\
\hline GWS (T1) & 70.55 & 67.77 & 73.45 & 17.38 & $20-104$ & .83 \\
\hline GWS (T2) & 71.90 & 63.61 & 75.57 & 18.98 & 17-108 & .93 \\
\hline SSGS_Shame (T1) & 7.83 & 8.37 & 7.35 & 3.55 & $5-19$ & .82 \\
\hline SSGS-Shame (T2) & 7.70 & 9.02 & 6.95 & 3.95 & $5-23$ & .88 \\
\hline SSGS_Guilt (T1) & 9.69 & 10.65 & 9.00 & 4.61 & $5-24$ & .85 \\
\hline SSGS_Guilt (T2) & 8.89 & 11.17 & 8.08 & 4.63 & $5-25$ & .90 \\
\hline
\end{tabular}

NOTE: PRQC = Perceived Relationship Quality Components Scale; KMS = Kansas Marital Satisfaction Scale; RAS = Relationship Assessment Scale; RSS = Relationship Satisfaction Scale; CES-D = Center for Epidemiological Studies Depression Scale; STAI = State-Trait Anxiety Inventory; GWS = General Well-Being Schedule; SSGS = State Shame and Guilt Scale; T1 = Time 1; T2 = Time 2.

Infidelity was operationalized using an inclusive definition when testing the proposed model. More specifically, responses from the three infidelity measures (i.e., objective, subjective-self, subjective-partner) were consolidated, such that an individual was considered to have been unfaithful if he or she endorsed extradyadic behavior on any of the questionnaires. Using these criteria, at Time 1 a total of 65 participants (23\% of the sample) reported engaging in infidelity within the past month. At Time 2, 41 participants (14\% of the sample) reported engaging in infidelity between Time 1 and Time $2 .{ }^{4}$

At Time $1,15 \%$ of those who had engaged in infidelity labeled their behavior as physical infidelity, 57\% labeled it emotional infidelity, and 15\% labeled it both physical and emotional infidelity. The remaining 13\% of participants did not classify their infidelity. As in Study 1, approximately one third of these participants $(32 \%)$ reported "one-night stands" or involvements lasting less than 24 hours. Others (43\%) described extradyadic relationships lasting from 1 to 4 weeks; relatively few participants $(14 \%)$ endorsed more longterm involvements. More than half of the participants $(52 \%)$ reported that the infidelity was still ongoing, $20 \%$ reported that the infidelity had ended within the past week, and the remaining $28 \%$ reported that it had ended within the past month. Only $18 \%$ of those who had engaged in infidelity reported that their primary partner was fully aware of the infidelity, $21 \%$ reported that their partner knew some of details of the infidelity, and the remaining $61 \%$ reported that their partner was unaware of their extradyadic involvement or that they were unsure of their partners' level of awareness.
As previously mentioned, 50 of the original participants were not included in the final sample because their relationships had broken up by Time 2 . Twentynine of these individuals had reported infidelity at Time 1 , and these individuals were compared with participants whose relationships sustained despite the occurrence of infidelity. MANOVAs suggested that individuals whose relationships ended following infidelity reported significantly different levels of psychological distress, $F(5,80)=3.77, p<.005$, and relationship satisfaction, $F(4,82)=12.56, p<.001$, at Time 1 than couples who stayed together despite the occurrence of infidelity. Univariate analyses revealed that when compared with partners who stayed together despite infidelity, those who broke up following infidelity reported greater depressive symptoms, $F(1,87)=$ $14.82, p<.001$; greater anxiety, $F(1,86)=14.60, p<$ .001 ; greater shame, $F(1,87)=4.74, p<.05$; greater guilt, $F(1,87)=4.26, p<.05$; and lower well-being, $F(1,85)=8.69, p<.005$. Furthermore, individuals who broke up following infidelity reported lower Time 1 relationship satisfaction on all four measures when compared with those that stayed together: PRQC, $F(1$, $87)=22.79, p<.001$; KMS, $F(1,87)=38.36, p<.001$; RAS, $F(1,87)=42.28, p<.001$; and RSS, $F(1,87)=$ $15.44, p<.001$.

\section{Measurement Model}

Consistent with a two-step approach, a confirmatory factor analysis (CFA) measurement model was first tested in which all paths were replaced with covariances. The 


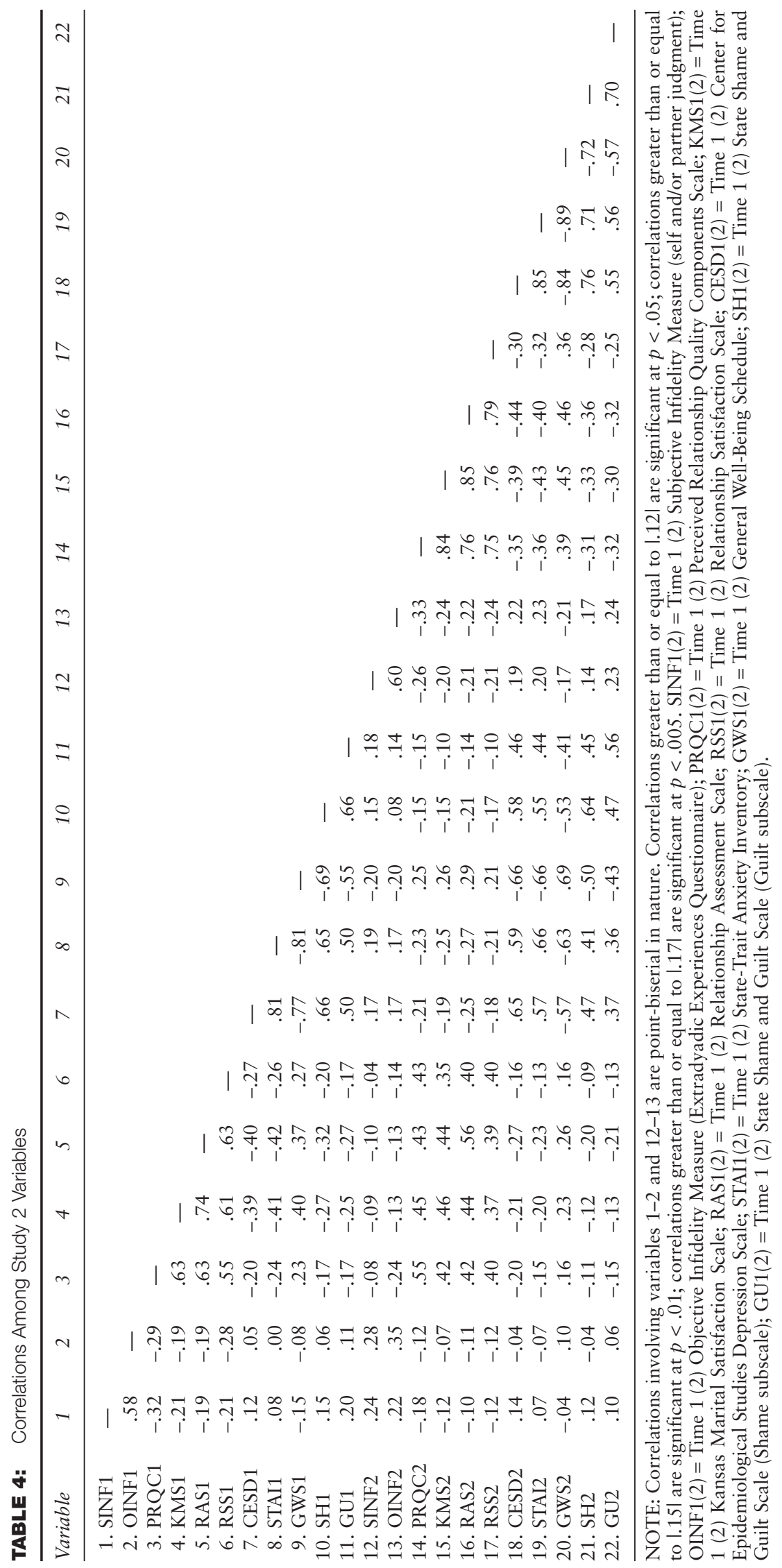


measurement model adequately fit the data, $\chi^{2}(34)=$ $74.94, p=.0001$, comparative fit index $(\mathrm{CFI})=.86$, Tucker-Lewis index (TLI) $=.96$, root mean square error of approximation (RMSEA) $=.07$. The standardized loadings of all factor indicators were significant, ranging from .64 to .94 for the psychological distress indicators and from .70 to .95 for the relationship satisfaction indicators. Thus, the basic measurement model appeared to be satisfactory. However, it was important to test for measurement invariance over time by imposing equality constraints on the factor loadings of each repeated measures indicator. The relative fit of this model did not differ significantly from that of the unconstrained model, $\Delta \chi^{2}(6)=11.16, p=.08$, suggesting that the factor loadings of each indicator did not differ markedly over time. Although the fit of this measurement model was acceptable, modification indices suggested that the within-time measurement errors of guilt and shame were correlated at Time 1 and Time 2, and the model was adjusted accordingly. This final measurement model provided an adequate fit to the data, $\chi^{2}(31)=58.18, p=.002, \mathrm{CFI}=.91$, TLI $=.97$, RMSEA $=.06$, and thus it was then appropriate to test the structural portion of the model.

\section{Path Model}

After estimating an acceptable measurement model, the CFA model was respecified as a hybrid model. The fit of this model was essentially identical to that of the CFA measurement model, $\chi^{2}(31)=58.18, p=.002$, CFI $=$ .91 , TLI $=.97$, RMSEA $=.06 .^{5}$ As desired, the factor loadings were extremely similar to those of the CFA model, indicating that assumptions about measurement were robust to changes in structural relations among the latent variables (Kline, 1998). Thus, this final model (see Figure 3) was retained and it was appropriate to proceed with interpretation of the various paths. ${ }^{6}$

Cross-sectional results. Cross-sectional findings were consistent with past research. Infidelity and psychological distress were correlated at both Time $1(r=.19, p<$ $.05)$ and Time $2(r=.16, p<.01)$. Infidelity was negatively related to relationship satisfaction (Time 1: $r=$ $-.36, p<.001$; Time $2: r=-.23, p<.01$ ), and relationship satisfaction and psychological distress were negatively correlated at both assessments (Time $1: r=-.45$, $p<.001$; Time 2: $r=-.31, p<.001$ ).

Longitudinal results. Surprisingly, Time 1 infidelity was unrelated to relationship satisfaction $(\beta=-.01, p>.10)$ and psychological distress $(\beta=.00, p>.10)$ at Time 2 , nor was Time 1 relationship satisfaction associated with infidelity $(\beta=.01, p>.10)$ or psychological distress $(\beta=.09, p>.10)$ at Time 2 . Although psychological distress at Time 1 did not predict Time 2 relationship satisfaction $(\beta=-.03, p>.10)$, greater distress predicted infidelity at Time $2(\beta=.23, p<.05)$. As hypothesized, stability coefficients for infidelity $(\beta=.43, p<.001)$, relationship satisfaction $(\beta=.57, p<.001)$, and psychological distress $(\beta=.80, p<.001)$ across time were significant.

Testing different definitions of infidelity. Given that we used an inclusive definition of infidelity, combining subjective, partner-based, and objective reports when testing the model, it was important to consider how the model results might differ based on which report was used. Thus, the model was reestimated separately for each of the three infidelity variables. Results were consistent with the original path model, as the significance of the various pathways remained unchanged. These results suggested that the model fit did not differ based on which reports of infidelity were used. However, the various infidelity variables were moderately to highly correlated with one another. Subjective-self and subjective-partner reports were significantly associated at both time points $(r s=.71$ and .78 at Time 1 and Time 2 , respectively; $p \mathrm{~s}<.005)$, as were subjective-self and objective reports of infidelity $(r s=.61$ and .59 at Time 1 and Time 2, respectively; $p s<.005$ ). Correlations between subjective-partner and objective reports of infidelity were .55 at Time 1 and .60 at Time 2, s $<.005$.

\section{Discussion}

The current study examined the associations among psychological distress, relationship satisfaction, and infidelity over time within a sample of college students in dating relationships. Psychological distress, relationship satisfaction, and infidelity were significantly correlated with one another at each assessment, replicating findings from previous studies. In addition, greater psychological distress at the initial assessment predicted a higher likelihood of infidelity 1 month later.

\section{Infidelity and Psychological Distress}

Cross-sectional analyses revealed that infidelity and psychological distress were positively associated at Time 1 and Time 2. Individuals who reported greater levels of distress were more likely to endorse infidelity. These findings replicated those of Study 1 and supported past research that has documented an association between infidelity and psychological distress.

Longitudinal analyses showed that psychological distress at Time 1 predicted Time 2 infidelity. This finding lends support to a compensation model of infidelity, in 


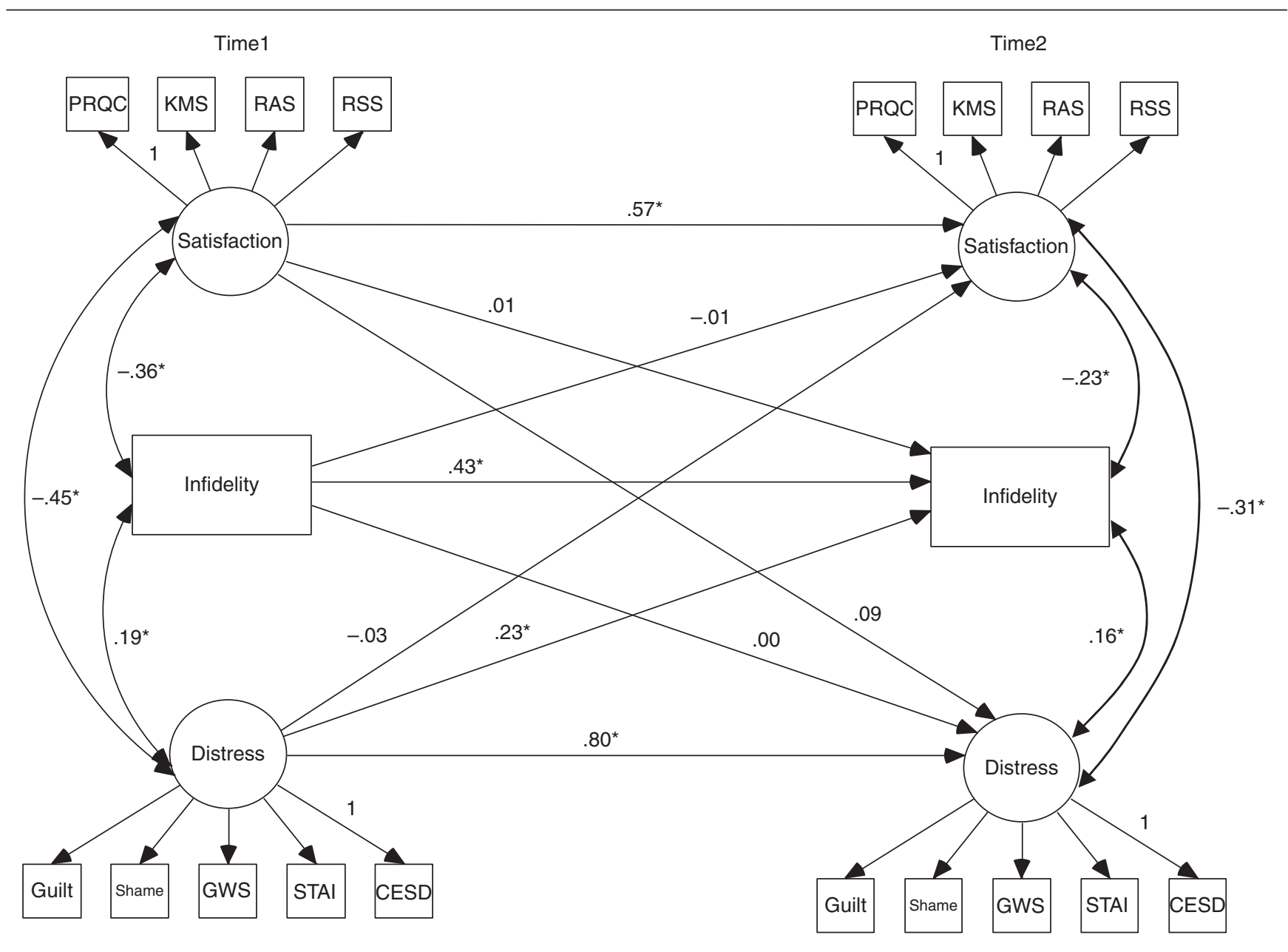

Figure 3 Final hybrid model.

NOTE: For clarity purposes, residual variances, errors, and disturbances are not included. PRQC = Perceived Relationship Quality Components Scale; KMS = Kansas Marital Satisfaction Scale; RAS = Relationship Assessment Scale; RSS = Relationship Satisfaction Scale; GWS = General Well-Being Schedule; STAI = State-Trait Anxiety Inventory; CESD = Center for Epidemiological Studies Depression Scale. $* p<.05$.

which individuals are most likely to engage in extradyadic behavior at times when they feel distressed, perhaps in an effort to improve their emotional state (e.g., Atwood \& Seifer, 1997). It is plausible that receiving romantic or sexual attention from another person beside one's partner could boost a distressed individual's self-esteem and serve as a form of reassurance. However, infidelity did not actually alleviate psychological distress in the current study. More broadly, the current findings are consistent with research that suggests that psychopathology is associated with higher rates of extradyadic behavior (e.g., Greeley, 1994).

Although there was a significant association between initial psychological distress and infidelity at Time 2, the reverse was not true, in that Time 1 infidelity was not related to subsequent psychological distress. However, it is possible that postinfidelity distress subsided before the Time 2 assessment. Some studies have shown that dissonance can be reduced when individuals are provided with opportunities to affirm valued aspects of the self (e.g., Steele \& Liu, 1983). Perpetrators might also have adjusted their attitudes toward infidelity, as this form of rationalization is thought to ease psychological discomfort (Aronson, Blanton, \& Cooper, 1995). Consistent with the victim-perpetrator literature, individuals might minimize their unfaithful behavior and alter their accounts of it in a self-serving manner (e.g., Zechmeister $\&$ Romero, 2002). It is also possible that the link between infidelity and psychological distress was stronger among unfaithful participants whose relationships ended before Time 2 and thus were not included in the final sample. These individuals reported greater 
distress at Time 1 than did individuals whose relationships remained intact at Time 2 . However, it would be difficult to determine whether Time 2 psychological distress among these individuals was related to infidelity (e.g., Beach et al., 1985) or relationship dissolution (e.g., Sbarra \& Emery, 2005).

Alternatively, the nonsignificant association between Time 1 infidelity and Time 2 psychological distress could be related to our use of a dating sample. It may be that college students in dating relationships experience less distress in the aftermath of infidelity than individuals in more committed relationships (e.g., marriage). From an evolutionary perspective, being unfaithful while in a dating relationship may represent an effective mate selection strategy and therefore result in less perpetrator distress. More specifically, short-term mating behaviors such as infidelity allow individuals to assess prospective long-term mates (Buss \& Schmitt, 1993), refine long-term mate preferences (Greiling \& Buss, 2000), or even find a better mate (Symons, 1979). Thus, the possibility that infidelity predicts psychological distress should be investigated further in future research, particularly within married samples.

\section{Relationship Satisfaction}

Contrary to the study hypotheses, initial levels of relationship satisfaction did not predict infidelity at Time 2. Although this finding may seem surprising in light of previous research suggesting a negative association between relationship satisfaction and extradyadic involvement, the majority of previous studies have been cross-sectional in nature and have assessed satisfaction retrospectively. Indeed, when looking within time, the current study also found that low levels of relationship satisfaction were associated with higher rates of infidelity. These results suggest that although individuals who engage in infidelity may be dissatisfied with their primary relationships, this dissatisfaction does not appear to drive extradyadic involvement. Consistent with this, some researchers have questioned whether dissatisfaction predicts extradyadic involvement (i.e., Atkins, Dimidjian, \& Jacobson, 2001) and have argued that satisfaction might not be associated with infidelity after controlling for other relationship variables such as trust and intimacy (Atkins, 2003).

Interestingly, the results of the present investigation also showed that Time 1 infidelity failed to predict relationship satisfaction at Time 2. Individuals who engaged in extradyadic behaviors did not appear to experience significant decreases in satisfaction within their primary relationships. The nonsignificant associations between infidelity and relationship satisfaction across time suggest that these variables are not causally related but may covary with one another. It is also possible that a third factor (e.g., personality) may drive both of these processes. However, it is important to note that the individuals whose relationship satisfaction declined most following infidelity may have been those who were excluded from the current sample because of relationship dissolution. These individuals did report lower relationship satisfaction at Time 1 than participants whose relationships remained intact following infidelity. This dissatisfaction may have led to relationship dissolution before Time 2. Regardless, the results of the current study reveal the need to consider how nonrelationship variables, such as general psychological distress, may be predictive of infidelity.

\section{GENERAL DISCUSSION}

In the growing literature on infidelity, the current studies are among the first to explore psychological distress in individuals who engage in extradyadic behavior. Study 1 replicated and extended past research, suggesting that infidelity is associated with elevated levels of psychological distress among college students in dating relationships. However, the cross-sectional nature of the data precluded inferences regarding the direction of effects. Thus, a second study examined the interrelationships among infidelity, psychological distress, and relationship satisfaction over a 1-month period. Results suggested that psychological distress was associated with a higher likelihood of engaging in later infidelity.

\section{Infidelity Among College Students}

Rates of infidelity in the current samples were fairly consistent with other studies of infidelity among college students (e.g., Oikle, 2003). However, these rates far exceeded those obtained in married samples (e.g., Choi, Catania, \& Dolcini, 1994), suggesting that infidelity is a more common occurrence in dating relationships. Interestingly, Study 2 revealed that the reported rates of infidelity varied based on how the questions were phrased. Although objective reports, subjective selfbased, and partner-based reports of infidelity were strongly correlated, there was a surprising amount of variability. These findings suggest that one individual's perception of extradyadic behavior is not necessarily consistent with what that individual's partner and/or the general public would consider to be infidelity. These results have interesting implications regarding the definition and measurement of infidelity. Given that infidelity is considered to be any behavior that violates the commitment to an exclusive relationship (e.g., Glass, 2002) and thus varies based on the expectations of a 
particular union, one might argue that subjective and partner-based reports of infidelity should be used to measure infidelity. However, the results of the present investigation suggest that this issue may be inconsequential in correlational analyses, as subjective, partner-based, and objective reports of infidelity yielded the same pattern of findings when testing the proposed model.

\section{Psychological Distress as a Precursor of Infidelity: Potential Mechanisms}

Although the present studies support the idea that psychological distress predicts later involvement in infidelity, they were not designed to provide data on the mechanisms underlying this association. What might these mechanisms be? One mechanism may involve the tendency of individuals to make poor decisions when under stress, as they fail to consider all available alternatives before making a decision (e.g., Keinan, 1987). Impaired decision making is also associated with depressive and anxious symptoms (Metzger, Miller, Cohen, \& Sofka, 1990; Murphy et al., 2001). Thus, one possibility is that individuals do not make adaptive relationship decisions when distressed and therefore are more likely to engage in relationship-destructive behaviors such as infidelity.

The current findings could also be understood within the framework of sexual strategies theory (Buss \& Schmitt, 1993), which suggests that individuals are motivated to employ short-term and/or long-term mating strategies depending on the potential costs and benefits in a given situation. In the context of psychological distress, an individual may be more open to short-term mating strategies such as infidelity if the potential benefits outweigh the costs. For example, one may believe that an affair could improve one's mood while requiring little investment or risk of getting caught. Indeed, both men and women reported that a potential benefit of short-term extra-pair mating was having a sexual partner who made them feel good about themselves (Greiling \& Buss, 2000). Similarly, Allen and Baucom (2004) found that a need to boost one's self-esteem/feel desirable was cited as a reason for infidelity within an undergraduate sample; this was particularly true for individuals with fearful or preoccupied attachment styles. Thus, it is possible that psychological distress itself may predict an increase in short-term mating behaviors such as infidelity.

Alternatively, the link between psychological distress and subsequent infidelity could be related to coping strategies. Individuals suffering from psychological distress may rely on a variety of coping strategies to improve their mental state, such as avoidance coping (Holahan, Moos, Holahan, Brennan, \& Schutte, 2005).
Infidelity could be considered a form of escape or avoidance coping, as it may allow individuals to avoid directly dealing with the source of their distress. However, whereas avoidance coping is generally believed to further exacerbate distress (e.g., Holahan et al., 2005), infidelity did not appear to exacerbate or alleviate distress in the current study. Alternatively, for some distressed individuals, engaging in infidelity may represent a form of emotion-focused coping through which the individual is able to decrease his or her negative emotional experience or seek social support (Carver, Scheier, $\&$ Weintraub, 1989). In sum, there are several plausible mechanisms that may account for the association between psychological distress and infidelity, and it is important for future research to explore these potential mediators.

\section{Limitations and Future Directions}

The findings of the current study must be interpreted in light of several limitations. First, our use of a college sample limits the extent to which the present results might generalize to other samples. For example, given the lower degree of commitment associated with dating relationships as compared to marriage (e.g., Forste \& Tanfer, 1996), the current results may be an underestimate of the postinfidelity distress that would be found in married samples. In addition, future research might benefit from studying both relationship partners to capture how infidelity, satisfaction, and distress interact at the dyadic level. It is also important to note that our sample included only couples that remained together after infidelity. It would be interesting to explore the association between distress and infidelity among perpetrators whose relationships dissolved following an affair. Notably, these individuals reported greater psychological distress and lower relationship satisfaction at Time 1 than participants whose relationships remained intact. Furthermore, it will be essential to identify variables that may mediate the associations tested in the current study and to consider other potential moderators such as attachment style (Allen \& Baucom, 2004) or sociosexual orientation (e.g., Simpson \& Gangestad, 1991).

\section{Conclusion}

Despite its limitations, the present research makes several valuable contributions to the romantic relationships literature. Study 1 revealed the broad range of psychological distress experienced by perpetrators of dating infidelity, and Study 2 represented the first longitudinal investigation of infidelity, psychological distress, and relationship satisfaction in dating relationships. Although initial reports of extradyadic involvement did 
not predict later psychological distress, psychological distress at Time 1 was associated with a greater likelihood of subsequent infidelity. These results suggest that psychological distress is best described as a precursor of dating infidelity and highlight the importance of studying nonrelationship variables when attempting to predict infidelity. It is important for future research to further examine the association between psychological distress and infidelity and to identify variables that may underlie this association.

\section{NOTES}

1. This 4-month requirement is common in studies of romantic relationships (e.g., Sbarra \& Emery, 2005), as it reduces the risk of sampling unstable, fledging relationships that may not be representative of more committed relationships.

2. To investigate the possibility of a gender interaction, a second MANOVA was conducted that included gender as an independent variable. The Infidelity $\times$ Gender interaction was not significant, $F(8$, 272) $=.662, p>.05$.

3. Mplus was used because it could accommodate both continuous and categorical data modeling, as well as missing data. Missing data were assumed to be missing at random and were considered missing as a function of the observed covariates in that the probabilities of values being missing could be predicted by observed variables (L. K. Muthén \& Muthén, 1998). Although this assumption is difficult to evaluate, a comparison of cases with and without missing data across Time 1 study variables with an alpha level of .005 revealed no significant differences $(p s>.10)$.

4. Twenty-one new cases of infidelity were reported at Time 2 , and 40 participants who endorsed infidelity at Time 1 were no longer engaged in this behavior at Time 2 .

5. A chi-square difference test could not be conducted because the structural and measurement models were not nested and they estimated the same number of parameters.

6. A post hoc moderation analysis was conducted to examine whether gender moderated any of the model pathways. Using an exploratory multiple group modeling approach, paths were constrained to be equal across gender groups, and modification indices were used to identify which paths should be freed to significantly improve the model chi-square. With paths constrained across gender groups, the model adequately fit the data, $\chi^{2}(24)=26.41, p=.33$, comparative fit index $=.99$, Tucker-Lewis index $=.99$, root mean square error of approximation $=.03$. This suggests that the associations within the model were not moderated by gender.

\section{REFERENCES}

Allen, E. S., Atkins, D. C., Baucom, D. H., Snyder, D. K., Gordon, K. C., \& Glass, S. P. (2005). Intrapersonal, interpersonal, and contextual factors in engaging in and responding to extramarital involvement. Clinical Psychology: Science and Practice, 12, 101-130.

Allen, E. S., \& Baucom, D. H. (2004). Adult attachment and patterns of extradyadic involvement. Family Process, 43(4), 467-488.

Aronson, J., Blanton, H., \& Cooper, J. (1995). From dissonance to disidentification: Selectivity in the self-affirmation process. Journal of Personality and Social Psychology, 68(6), 986-996.

Atkins, D. C. (2003). Infidelity and marital therapy: Initial findings from a randomized clinical trial. Unpublished doctoral dissertation, University of Washington, Seattle.

Atkins, D. C., Dimidjian, S., \& Jacobson, N. S. (2001). Why do people have affairs? Recent research and future directions about attributions for extramarital involvement. In V. Manusov \& J. H. Harvey (Eds.), Attribution, communication behavior, and close relationships (pp. 305-319). New York: Cambridge University Press.

Atwater, L. (1979). Getting involved: Women's transition to first extramarital sex. Alternative Lifestyles, 2, 33-68.

Atwood, J. D., \& Seifer, M. (1997). Extramarital affairs and constructed meanings: A social constructionist therapeutic approach. American Journal of Family Therapy, 25(1), 55-75.

Baumeister, R. F. (1998). The self. In D. T. Gilbert \& S. T. Fiske (Eds.), The handbook of social psychology (pp. 680-740). New York: McGraw-Hill.

Baumeister, R. F., Stillwell, A. M., \& Heatherton, T. F. (1995). Personal narratives about guilt: Role in action control and interpersonal relationships. Basic and Applied Social Psychology, 17(1/2), 173-198.

Beach, S. R., Jouriles, E. N., \& O’Leary, K. (1985). Extramarital sex: Impact on depression and commitment in couples seeking marital therapy. Journal of Sex \& Marital Therapy, 11(2), 99-108.

Beach, S. R., \& O'Leary, K. (1993). Marital discord and dysphoria: For whom does the marital relationship predict depressive symptomatology? Journal of Social and Personal Relationships, 10(3), 405-420.

Beck, A. T., Epstein, N., Brown, G., \& Steer, R. A. (1988). An inventory for measuring clinical anxiety: Psychometric properties. Journal of Consulting and Clinical Psychology, 56, 893-897.

Beck, A. T., \& Steer, R. A. (1990). Manual for the Beck Anxiety Inventory. San Antonio, TX: Psychological Corporation.

Betzig, L. (1989). Causes of conjugal dissolution: A cross-cultural study. Current Anthropology, 30, 654-676.

Buss, D. M., Larsen, R. J., Westen, D., \& Semmelroth, J. (1992). Sex differences in jealousy: Evolution, physiology, and psychology. Psychological Science, 3(4), 251-255.

Buss, D. M., \& Schmitt, D. P. (1993). Sexual strategies theory: An evolutionary perspective on human mating. Psychological Review, 100(2), 204-232.

Buunk, B. P., \& van Driel, B. (1989). Variant lifestyles and relationships. Newbury Park, CA: Sage.

Cameron, J. J., Ross, M., \& Holmes, J. G. (2002). Loving the one you hurt: Positive effects of recounting a transgression against an intimate partner. Journal of Experimental Social Psychology, 38, 307-314.

Carver, C. S., Scheier, M. F., \& Weintraub, J. K. (1989). Assessing coping strategies: A theoretically based approach. Journal of Personality and Social Psychology, 56, 267-283.

Choi, K. H., Catania, J. A., \& Dolcini, M. (1994). Extramarital sex and HIV risk behavior among US adults: Results from the National AIDS Behavioral Survey. American Journal of Public Health, 84(12), 2003-2007.

Drigotas, S. M., Safstrom, C. A., \& Gentilia, T. (1999). An investment model prediction of dating infidelity. Journal of Personality and Social Psychology, 77(3), 509-524.

Dupuy, H. J. (1978, October). Self-representations of general psychological well-being of American adults. Paper presented at the American Public Health Association Meeting, Los Angeles, CA.

Elbaum, P. L. (1981). The dynamics, implications and treatment of extramarital sexual relationships for the family therapist. Journal of Marital \& Family Therapy, 7(4), 489-495.

Fazio, A. F. (1977). A concurrent validational study of the NCHS General Well-Being Schedule. Hyattsville, MD: U.S. Department of Health, Education, and Welfare.

Fletcher, G. J. O., Simpson, J. A., \& Thomas, G. (2000). A measurement of perceived relationship quality components: A confirmatory factor analytic approach. Personality and Social Psychology Bulletin, 26, 340-354.

Forste, R., \& Tanfer, K. (1996). Sexual exclusivity among dating, cohabiting, and married women. Journal of Marriage and Family, 58(1), 33-47.

Geiss, S. K., \& O’Leary, K. D. (1981). Therapist ratings of frequency and severity of marital problems: Implications for research. Journal of Marital \& Family Therapy, 7(4), 515-520.

Glass, S. P. (2002). Couple therapy after the trauma of infidelity. In A. S. Gurman \& N. S. Jacobson (Eds.), Clinical handbook of couple therapy (3rd ed., pp. 488-507). New York: Guilford. 
Glass, S. P., \& Wright, T. L. (1992). Justifications for extramarital relationships: The association between attitudes, behaviors, and gender. Journal of Sex Research, 29(3), 361-387.

Greeley, A. (1994). Marital infidelity. Society, 31, 9-13.

Greiling, H., \& Buss, D. M. (2000). Women's sexual strategies: The hidden dimension of extra-pair mating. Personality and Individual Differences, 28, 929-963.

Hall, J. H., \& Fincham, F. D. (2008). The temporal course of selfforgiveness. Journal of Social and Clinical Psychology, 27(2), 174-202.

Hendrick, S. S. (1988). A generic measure of relationship satisfaction. Journal of Marriage and Family, 50, 93-98.

Himmelfarb, S., \& Murrell, S. A. (1983). Reliability and validity of five mental health scales in older persons. Journal of Gerontology, $38,333-339$

Holahan, C. J., Moos, R. H., Holahan, C. K., Brennan, P. L., \& Schutte, K. K. (2005). Stress generation, avoidance coping, and depressive symptoms: A 10-year model. Journal of Consulting and Clinical Psychology, 73(4), 658-666.

Hunt, N. (1974). Sexual behavior in the 1970s. Chicago: Dell.

Jones, W. H., Moore, D. S., Schratter, A., \& Negel, L. A. (2001). Interpersonal transgressions and betrayals. In R. M. Kowalski (Ed.), Behaving badly: Aversive behaviors in interpersonal relationships (pp. 233-256). Washington, DC: American Psychological Association.

Keinan, G. (1987). Decision making under stress: Scanning of alternatives under controllable and uncontrollable threats. Journal of Personality and Social Psychology, 52(3), 639-644.

Kline, R. B. (1998). Principles and practices of structural equation modeling. New York: Guilford.

Lawson, A. (1988). Adultery. New York: Basic Books.

Marschall, D. Saftner, J., \& Tangney, J. P. (1994). The State Shame and Guilt Scale. Unpublished manuscript, George Mason University, Fairfax, VA.

Metzger, R. L., Miller, M. L., Cohen, M., \& Sofka, M. (1990). Worry changes decision making: The effect of negative thoughts on $\operatorname{cog}$ nitive processing. Journal of Clinical Psychology, 46(1), 78-88.

Murphy, F. C., Rubinsztein, J. S., Michael, A., Rogers, R. D., Robbins, T. W., Paykel, E. S., et al. (2001). Decision-making cognition in mania and depression. Psychological Medicine, 31(4), 679-693.

Muthén, B. O., \& Muthén, L. K. (2004). Mplus (Version 3.11) [Computer software]. Los Angeles: Muthen \& Muthen.

Muthén, L. K., \& Muthén, B. O. (1998). Mplus user's guide (3rd ed.). Los Angeles: Muthen \& Muthen.

Oikle, J. M. (2003). The prediction and description of dating infidelity. Unpublished doctoral dissertation, University of Kansas, Lawrence.

Radloff, L. S. (1977). The CES-D Scale: A self-report depression scale for research in the general population. Applied Psychological Measurement, 1, 385-401.

Roscoe, B., Cavanaugh, L. E., \& Kennedy, D. R. (1988). Dating infidelity: Behaviors, reasons and consequences. Adolescence, 23(89), 35-43.

Rusbult, C. E. (1983). A longitudinal test of the investment model: The development (and deterioration) of satisfaction and commitment in heterosexual involvements. Journal of Personality and Social Psychology, 45, 101-117.

Sbarra, D. A., \& Emery, R. E. (2005). The emotional sequelae of nonmarital relationship dissolution: Analysis of change and intraindividual variability over time. Personal Relationships, 12, 213-232.

Schumm, W. R., Paff-Bergen, L. A., Hatch, R. C., Obiorah, F. C., Copeland, J. M., Meens, L. D., et al. (1986). Concurrent and discriminant validity of the Kansas Marital Satisfaction Scale. Journal of Marriage and Family, 48, 381-387.

Sheppard, V. J., Nelson, E. S., \& Andreoli-Mathie, V. (1995). Dating relationships and infidelity: Attitudes and behaviors. Journal of Sex \& Marital Therapy, 21(3), 202-212.

Simpson, J. A., \& Gangestad, S. W. (1991). Individual differences in sociosexuality: Evidence for convergent and discriminant validity. Journal of Personality and Social Psychology, 60(6), 870-883.

Spanier, G. B., \& Margolis, R. L. (1983). Marital separation and extramarital sexual behavior. Journal of Sex Research, 19(1), 23-48.

Spielberger, C. D., Gorsuch, R. L., \& Lushene, R. E. (1970). State-Trait Anxiety Inventory. Palo Alto, CA: Consulting Psychologists Press.

Spielberger, C. D., Gorsuch, R. L., Lushene, R. E., Vagg, P. R., \& Jacobs, G. A. (1983). Manual for the State-Trait Anxiety Inventory. Palo Alto, CA: Consulting Psychologists Press.

Steele, C. M., \& Liu, T. J. (1983). Dissonance processes as selfaffirmation. Journal of Personality and Social Psychology, 45, 5-19.

Symons, D. (1979). The evolution of human sexuality. New York: Oxford University Press.

Taylor, S. E., \& Brown, J. D. (1988). Illusion and well-being: A social psychological perspective on mental health. Psychological Bulletin, 103(2), 193-210.

Weiss, D. S., \& Marmar, C. R. (1997). The Impact of Event Scale-Revised. In J. P. Wilson \& T. M. Keane (Eds.), Assessing psychological trauma and PTSD (pp. 399-411). New York: Guilford.

Whisman, M. A., Uebelacker, L. A., \& Weinstock, L. M. (2004). Psychopathology and marital satisfaction: The importance of evaluating both partners. Journal of Consulting and Clinical Psychology, 72(5), 830-838.

Wiederman, M. W. (1997). Extramarital sex: Prevalence and correlates in a national survey. Journal of Sex Research, 34(2), 167-174.

Wiederman, M. W., \& Allgeier, E. R. (1996). Expectations and attributions regarding extramarital sex among young married individuals. Journal of Psychology \& Human Sexuality, 8(3), 21-35.

Wiederman, M. W., \& Hurd, C. (1999). Extradyadic involvement during dating. Journal of Social and Personal Relationships, 16(2), 265-274.

Wiggins, J. D., \& Lederer, D. A. (1984). Differential antecedents of infidelity in marriage. American Mental Health Counselors Association Journal, 6(4), 152-161.

Zechmeister, J. S., \& Romero, C. (2002). Victim and offender accounts of interpersonal conflict: Autobiographical narratives of forgiveness and unforgiveness. Journal of Personality and Social Psychology, 82, 675-686.

Received June 28, 2007

Revision accepted August 16, 2008 